\title{
From product to service business: Productization of product-oriented, use- oriented, and result-oriented business
}

\author{
E. Mustonen ${ }^{1}$, J. Harkonen ${ }^{1}$ and H. Haapasalo ${ }^{1}$ \\ ${ }^{1}$ Industrial Engineering and Management, University of Oulu, Oulu, Finland \\ (erno.mustonen@oulu.fi)
}

\begin{abstract}
Companies considering a shift from manufacturing and selling physical products to selling services face several questions on service structure and repeatability. The current and potential offerings should be compared in the light of commercial and technical portfolio. The commercial offering visible to the customer needs to be productized and linked to the technical structure for services, including the needed processes and resources. From the financial viewpoint, the cost of delivering the offering should be known to be able to set a profitable price. Productization through a common product structure that acknowledges the commercial and technical views could be used as a tool to clarify the current and potential offerings and transform them into systematic and repeatable form that is comparable. The present study provides an example of using this kind of product structure to model a physical product offered as part of product-oriented, use-oriented, and result-oriented product-service systems. The presented product structure logic enables companies to clarify the offering, describe the processes and resources needed for delivering the offering, and evaluate its profitability.
\end{abstract}

Keywords - Productization, product structure, productservice system, PSS, servitization, service management

\section{INTRODUCTION}

Manufacturers have had a significant change from offering physical products into offering services [1]. This shift from selling solely physical products to selling services, servitization, can be described through three main categories of product-service systems (PSS): product-oriented, use-oriented, and result-oriented [2]. In product-oriented PSS, a physical product is still sold but with complementary services that relate to the physical product [3]. In use-oriented product-service systems, a company leases its physical product to the customer while taking care of the technical maintenance and retaining the ownership of the product [2]. In this Product-as-a-Service (PaaS) type of business model, a physical product is transformed into a means of production. In result-oriented PSS, the customer pays for the outputs the physical product produces [3]. The responsibility of fulfilling the customer's fundamental need is mostly on the service provider [2].

When considering the change, companies need to decide upon things such as, what elements should the service offering include, what resources are needed to deliver the offering, and how to price the services.
However, companies shifting into services are facing challenges in designing and delivering a modular and scalable offering and communicating the offering to the customers [4]. Additionally, understanding the needed capabilities to deliver the offering is seen difficult [5]. Due to lack of mutual understanding of products within companies, there exist inabilities to assess the profitability of individual services [6], which hinders product portfolio decision-making [7]. To be able to compare different PSS alternatives in this regard, the offerings should be modeled in a way that they can be delivered repeatably in a systematic manner with minimum changes.

In case of services, mutual understanding of products within a company can be created by modeling and systematizing common service processes [8-9]. Service processes, however, refer only to the technical levels of the product structure, and, thus, the offering should be structured on the commercial side as well to enable effective selling, delivering, and invoicing [10]. All configurable elements of a product that are visible to the customer, i.e. variants and options, should be visible in the commercial product portfolio. In addition, a link between what is sold and what is made should be maintained [11]. This can be achieved by using a product structure that acknowledges both the commercial and technical sides of the product portfolio. In this manner, an intangible service offering, and related service processes, can be productized, making them more systematic and tangible [10]. Reference [7] presented a product structure model that connects the commercial product structure levels, namely solutions, product families, product configurations, and sales items, to the technical portfolio. Sales items are the lowest commercial items in a product portfolio and are used to configure the products according to customer needs. Each sales item has a respective technical version item that is formed by assemblies, subassemblies, and components. While sales items and the commercial side of the portfolio define what is marketed and sold to the customer, version items and the technical side of the portfolio define what is produced [12]. The same logic has since been applied in practice to physical products [13] as well as service products [14-15]. In case of services, the version item is formed by service processes and subprocesses, which can be connected to the required service delivery resources [10]. The more result-oriented a service is, more freedom is left for the service provider to deliver the service [2], which enables a large variety of possibilities in the technical product structure. 
The previous literature has provided some examples of productizing physical products and services through a product structure that acknowledges both the commercial and technical portfolios. However, the examples do not provide enough support for productizing the same product as a physical product and as a service product for servitization considerations and decision-making. This study aims to improve understanding of using a systematic product structure to clarify the offering and enhance decision-making on servitization. Car is used as an example to productize a physical product as a productoriented, use-oriented, and result-oriented product-service system.

\section{METHODOLOGY}

In this study, the previous research on product structures concerning commercial and technical views was studied by conducting a brief literature review. Then, the logic of commercial and technical product portfolios $[7,10,13-15]$ was adapted to describe a case product sold as a product-oriented, use-oriented, and result-oriented PSS. Car was chosen as the case product due to its comprehensibility. The case product, Volkswagen Polo SE, was first modeled commercially as a product-oriented PSS based on the offering visible on the Volkswagen UK's official website [16] and its "Build your own" configurator. The configurator provided all the variants and options a customer could choose. The authors listed them as the sales items of the configurable Polo SE. Technical side of the portfolio was modeled hypothetically to a certain level, starting from each sales item's respective version item. After the case product was modeled as a product-oriented PSS, it was then modeled commercially and technically as a use-oriented PSS, car leasing service. Websites of several car leasing companies were inspected to gather understanding of common leasing service configuration possibilities. Again, the variants and options a customer could choose to configure the service were listed as the sales items of the leasing service. Their technical structures were described hypothetically. To model the case product commercially as a result-oriented PSS, a vehicle for hire/taxi ride, the website of Volkswagen Move [17] was utilized. Then, the technical portfolio was described hypothetically to a certain extent.

\section{RESULTS}

\section{A. Car as a product-oriented PSS}

Productization of car as a physical product is presented in Fig. 1. Configurable product Polo SE consists of several sales items, of which the customer chooses the most pleasing ones to get a car according to one's needs. Due to the vast number of the actual sales items on the company website, only some of them are presented in this example. The sales item Polo $S E$ is a basic sales item, forming most of the technical structure of the car. It is always included in the configuration. In addition, there are three engine sales item variants: 1.05 speed Manual, 1.0 TSI 5-speed Manual, and 1.0 TSI 7speed DSG; three color sales item variants: Pure white, Flash Red, and Black; and one optional service sales item,

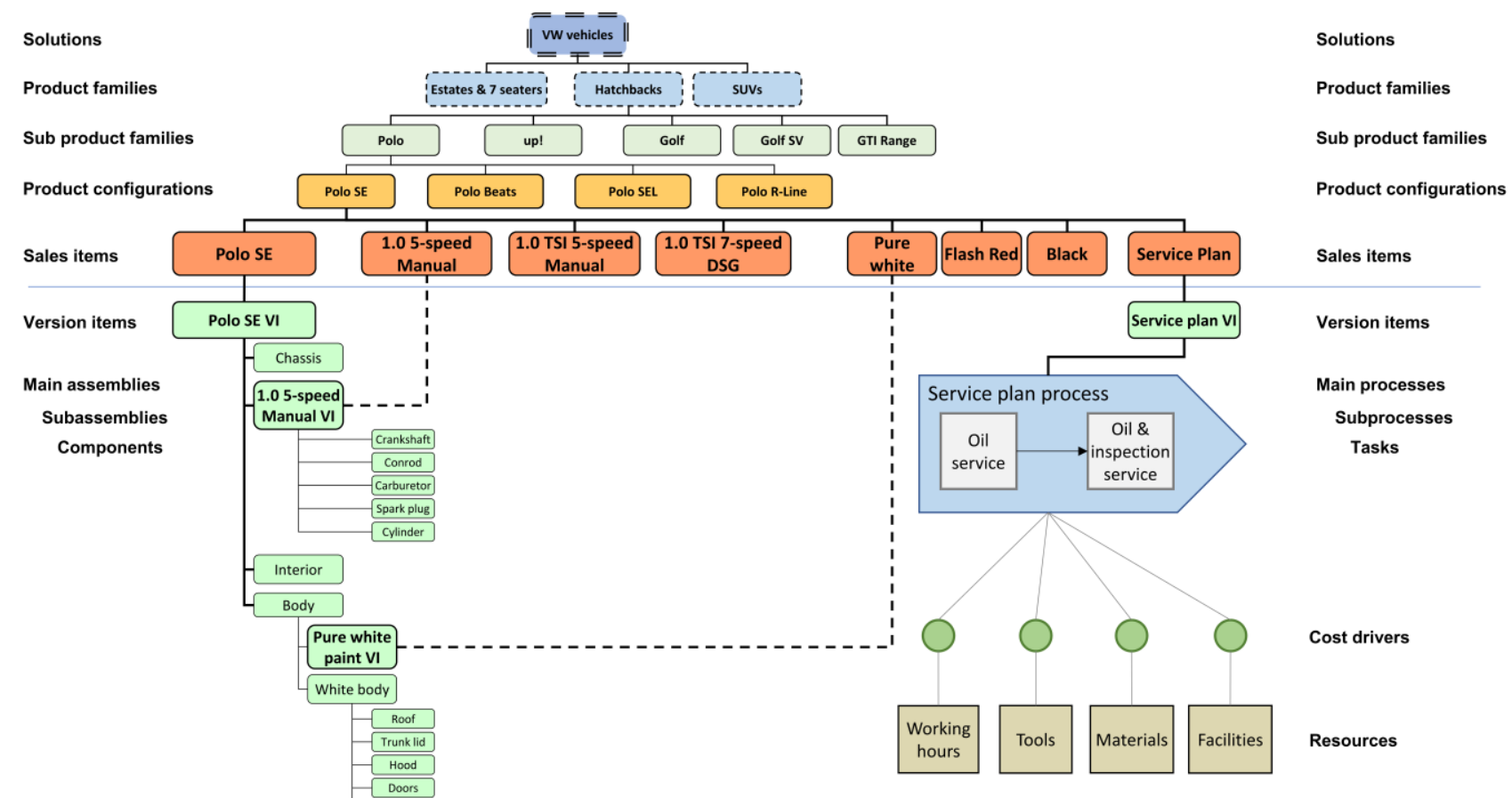

Fig. 1. Car as a product-oriented PSS. 
Service Plan. Thus, all customer-chosen variations reside on the commercial side of the portfolio. In this case, the customer has chosen a Pure white Polo SE with 1.0 5speed Manual engine and has chosen the optional Service Plan as well. Each of the sales items has a respective version item in the technical portfolio. Considering the physical sales items, the technical portfolio follows the same logic as configurable bills of materials. The main assembly of the version item (VI) Polo SE consists chassis, engine, interior, and body, which are further formed by subassemblies and components. The version items 1.0 5-speed Manual and Pure white reside beneath the Polo SE version item's assembly and are replaced in case the customer chooses alternative sales items. When it comes to the service sales item, the major difference in the technical portfolio compared to the physical ones is that, instead of bills of materials, now the technical side consists of bills of service processes/service blueprints, including oil service and oil \& inspection service processes in this case.

Profitability of the configuration can be calculated based on the sales items' prices and the respective version items' production costs. Production cost of each version item should remain unchanged no matter which configuration is chosen. If the cost changes significantly depending on the configuration, a new sales item (and a price for that) should be created to maintain the profitability. This applies also if the fit, form, or function of the version item is changed. Activity-based costing can be used to calculate the costs for service version items by linking the service processes to the resources through cost drivers.

\section{B. Car as a use-oriented PSS}

Productization of car as a leasing service is presented in Fig. 2. When productizing a leasing service, it is not the car, as a physical product, that is being configured anymore. Instead, service product is the one to be configured by service sales items, whereas the Polo SE 1.0 5-speed Manual Pure white car becomes a means of service production, a resource. The sales items the customer has chosen in the presented example are 30,000 $\mathrm{km}$ driving allowance and 1-year contract. The respective version items exist in the technical portfolio. The service process of the $30,000 \mathrm{~km}$ version item includes activities/subprocesses occurring during 30,000 km drive, whereas the service process of the 1-year contract version item includes activities/subprocesses occurring during 1 year.

Profitability of the service configuration can be calculated using the same logic as in the previous example based on the sales items' prices and the respective version items' costs. In this case, activity-based costing can be used to calculate all version items' costs. Cost drivers connect the processes and corresponding resources. Now, the car is productized as a resource for service production, instead of productizing it as a physical item. Cost drivers for $30,000 \mathrm{~km}$ version item relate to car maintenance, tire wear, and depreciation in car value per $30,000 \mathrm{~km}$, whereas cost drivers for 1-year contract version item relate to semiannual wheel change (change between summer and winter tires), car insurance and depreciation in car value per 1 year, and cleaning and inspection at the end of the leasing period.

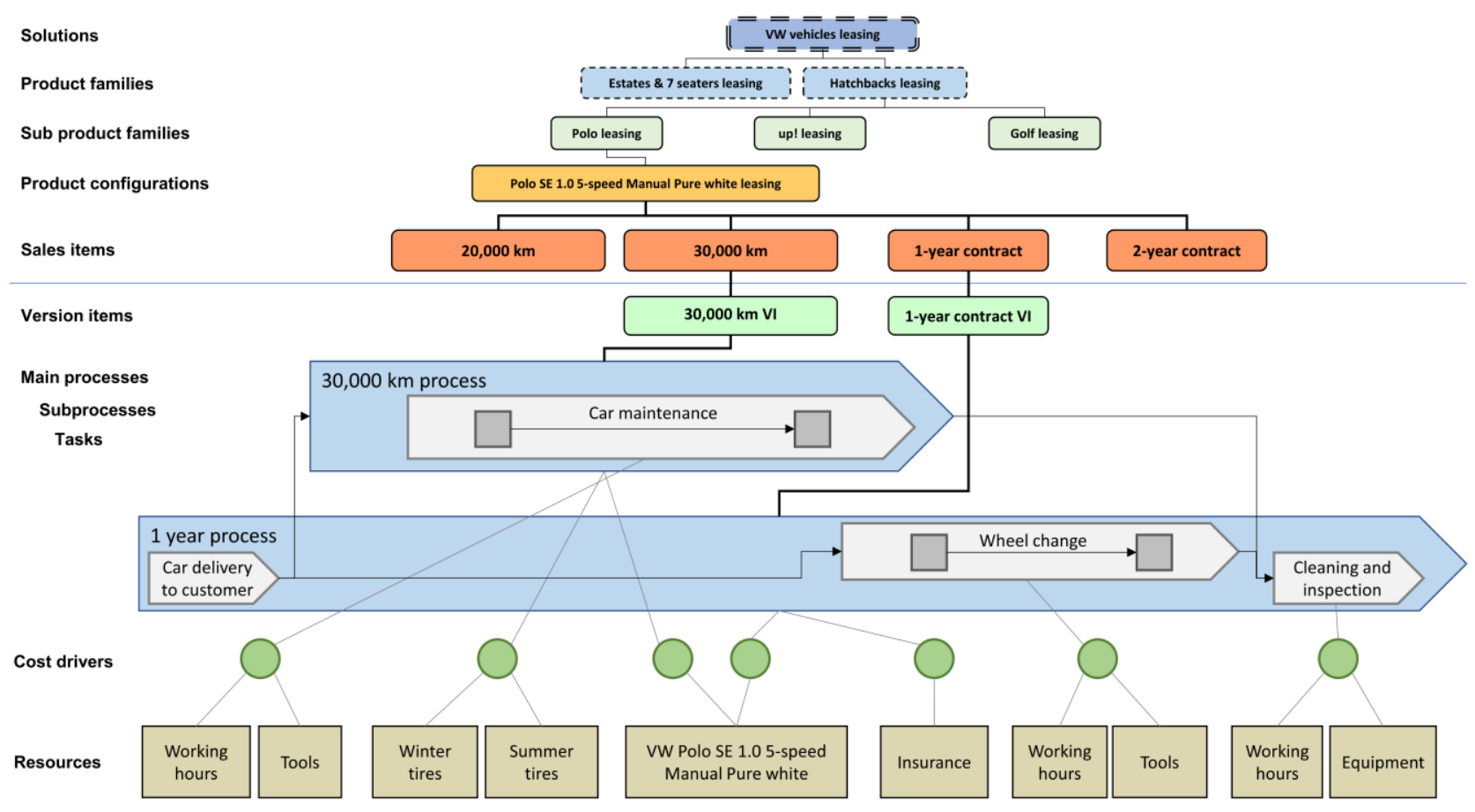

Fig. 2. Car as a use-oriented PSS. 


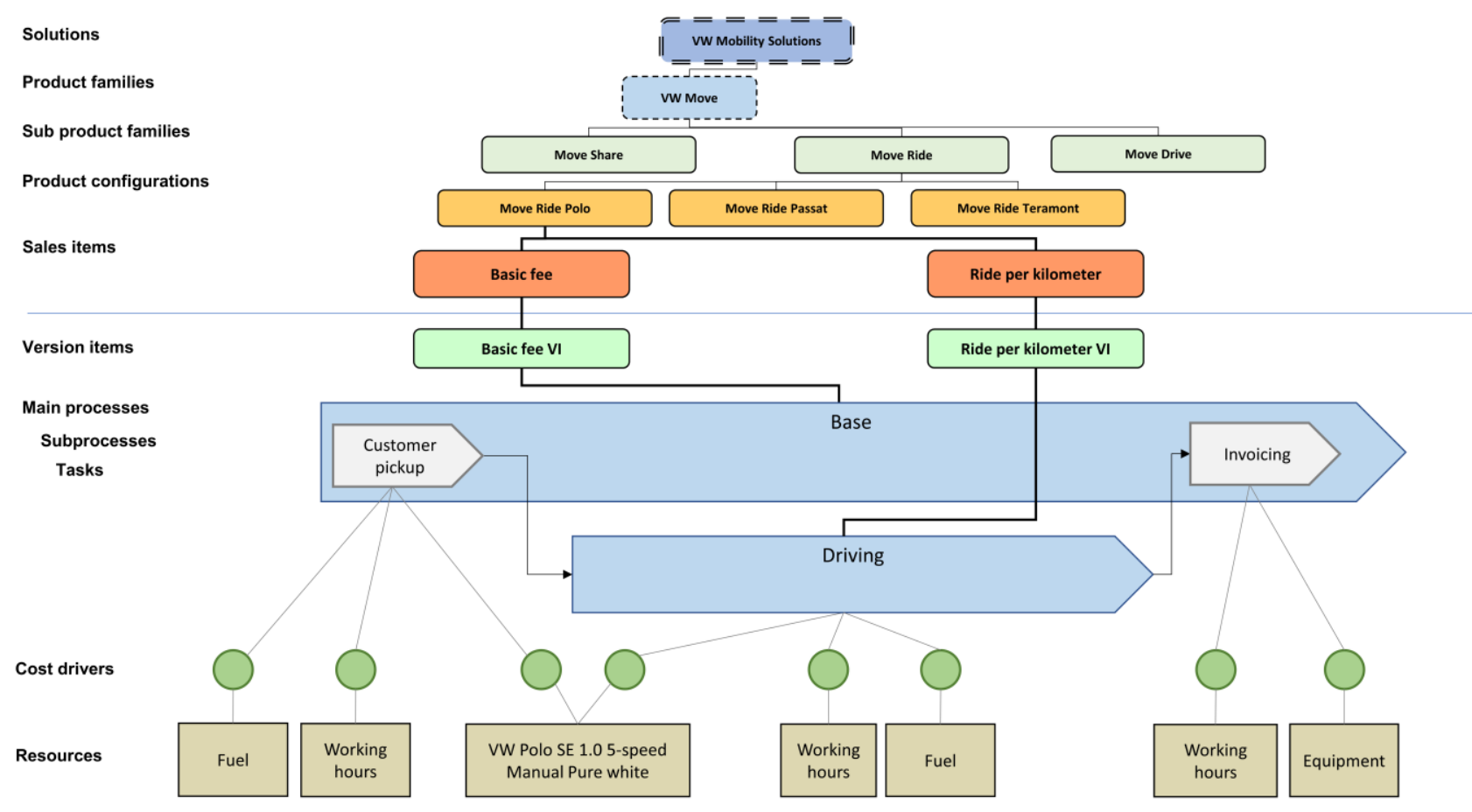

Fig. 3. Car as a result-oriented PSS.

\section{Car as a result-oriented PSS}

Productization of a taxi ride is presented in Fig. 3. The productization of the commercial portfolio follows quite closely the logic presented in the leasing service example. The sales items in this case consist of Basic fee and Ride per kilometer. On the technical side, Basic fee version item consists of processes such as invoicing and customer pickup, whereas Ride per kilometer version item is delivered through a driving process. However, taxi ride being a result-oriented PSS, the customer does not want to pay for the time spent on the ride but only for the result, distance traveled. This forms challenges in calculating the costs, and thus setting the prices for the sales items, as some costs (e.g. driver's salary, fuel) are more difficult to allocate due to varying driving environments (e.g. city center/highway, traffic) that affect the real costs per kilometer and ride.

As a solution to define the costs, some options can be considered. One of them is to evaluate a cost that would cover all different driving environments. Then, the prices would be set accordingly. The prices would not attract rides outside city centers, though, since lower fuel consumption and driver's salary per kilometer due to higher average speed outside city center would not be reflected in the prices. Therefore, a second option would be to divide Ride per kilometer sales item into several sales items according to drive in highway, city center, or during rush hour, whose prices would better reflect the costs of their respective version items. A modern option would be to use software to calculate accurate salary and fuel costs based on real-time traffic information in advance. The price would be agreed before the ride.

\section{CONCLUSION}

This study presented an example of productizing a physical product as a product-oriented PSS, use-oriented PSS, and result-oriented PSS by using a common product structure. The product structure should cover both the commercial side and the technical side of the product portfolio. The logic in productizing a commercial product portfolio is rather unchanged regardless whether productizing a physical product or a service. All customer-chosen variations should occur through sales items on the commercial side of the portfolio. The biggest difference in productization of physical products and services resides on the technical side of the portfolio. When productized as a physical product, the technical portfolio consists of assemblies, subassemblies, and components, whereas in case of services, the technical portfolio consists of service processes, subprocesses, and tasks. The physical product acts as a resource in service production. Profitabilities of physical products and services can be calculated based on the prices of the sold commercial sales items, and the costs of the respective version items.

For company managers, this study gives insight into comparing different servitization options. Manufacturing companies can use the presented product structure logic when considering whether to shift from manufacturing business to service business. The presented product structure logic clarifies the offering by defining what can be developed, marketed, sold, and delivered. Commercial 
productization helps especially marketing and sales activities to show customers what can be bought. Technical productization helps in defining the needed processes and resources for service production. Clarification enhances designing of a modular and scalable offering. It is not that uncommon that companies do not have an idea how large their offering is when all variants and optional items are considered. Through commercial and technical productization, the company gains an understanding of what it should be able to deliver to the customer. In addition, as the profitability of each available variant and option can be calculated by connecting the commercial and technical side of the product structure, analyses and decisions on the overall offering can be made.

The study is limited by considering only one case product, a car. However, the presented product structure logic can be applied to other products and industries as well. Applications could be for example selling a surface inspection device as a physical product, monthly feebased service, or pay-per-detection service; or selling lifted meters or tons instead of selling a crane. Other limitations include the commercial productization being based on companies' public web pages which do not always correspond to the companies' actual offerings, and technical productization being somewhat hypothetical. The productization logic presented in this paper should be tested in real life context for example with car manufacturers, rental agencies and taxi service providers.

\section{REFERENCES}

[1] C. Kowalkowski, H. Gebauer and R. Oliva, "Service growth in product firms: past, present, and future", Industrial Marketing Management, vol. 60, pp. 82-88, 2017.

[2] A. Tukker, "Eight types of product-service system: eight ways to sustainability? Experiences from suspronet", Business Strategy and the Environment, vol. 13, no. 4, pp. 246-260, 2004.

[3] T. S. Baines, H.W. Lightfoot, S. Evans, A. Neely, R. Greenough, J. Peppard, R. Roy, E. Shebab, A. Braganza, A. Tiwari, J. Alcock, J. Angus, M. Bastl, A. Cousens, P. Irving, M. Johnson, J. Kingston, H. Lockett, V. Martinez, P. Michele, D. Tranfield, I. Walton and H. Wilson, "State-ofthe-art in product service-systems", in Proceedings of the Institution of Mechanical Engineers. Part B, Journal of Engineering Manufacture, vol. 221, no. 10, pp. 1543-1552, 2007.

[4] A. Alghisi and N. Saccani, "Internal and external alignment in the servitization journey - overcoming the challenges", Production Planning \& Control, vol. 26, no. 14-15, pp. 1219-1232, 2015.
[5] A. Neely, "Exploring the financial consequences of the servitization of manufacturing", Operations Management Research, vol. 1, no. 2, pp. 103-118, 2008.

[6] A. Tolonen, H. Kropsu-Vehkapera and H. Haapasalo, "Product portfolio management - current challenges and preconditions", International Journal of Performance Management, vol. 4, no. 2, pp. 69-90, 2014.

[7] A. Tolonen, J. Harkonen and H. Haapasalo, "Product portfolio management - governance for commercial and technical portfolios over life cycle", Technology and Investment, vol. 5, no. 4, pp. 173-183, 2014.

[8] R. Lavikka, R. Smeds and M. Jaatinen, "Coordinating the service process of two business units towards a joint customer", Production Planning \& Control, vol. 20, no. 2, pp. 135-146, 2009.

[9] K. Valminen and M. Toivonen, "Seeking efficiency through productisation: a case study of small KIBS participating in a productisation project", The Service Industries Journal, vol. 32 , no. 2, pp. 273-289, 2012

[10] J. Harkonen, A. Tolonen and H. Haapasalo, "Service productisation: systematising and defining an offering", Journal of Service Management, vol. 28, no. 5, pp. 936971, 2017.

[11] C. Forza and F. Salvador, "Application support to product variety management", International Journal of Production Research, vol. 46, no. 3, pp. 817-836, 2008.

[12] H. Kropsu-Vehkapera and H. Haapasalo, "Defining product data views for different stakeholders", Journal of Computer Information Systems, vol. 52, no. 2, pp. 61-72, 2011.

[13] J. Harkonen, A. Tolonen and H. Haapasalo, "Modelling of construction products and services for effective productisation", Management, vol. 13, no. 4, pp. 335-353, 2018.

[14] J. Harkonen, A. Tolonen and H. Haapasalo, "Modelling of manufacturing services and processes for effective productisation", presented at the $20^{\text {th }}$ International Working Seminar on Production Economics, Innsbruck, 2018.

[15] S. Kuula, H. Haapasalo and A. Tolonen, "Cost-efficient cocreation of knowledge intensive business services", Service Business, vol. 12, no. 4, pp. 779-808, 2018.

[16] Volkswagen, "The official website for Volkswagen UK", 2019. [Online]. Available: https://www.volkswagen.co.uk. [Accessed: 21- May- 2019].

[17] Volkswagen, "Move by Volkswagen", 2018. [Online]. Available: https://www.move.rw. [Accessed: 24-May2019]. 